\title{
International mobility of students in Italy and the UK: does it pay off and for whom?
}

\author{
Béatrice d'Hombres ${ }^{1} \cdot$ Sylke V. Schnepf ${ }^{1}$
}

Accepted: 18 September 2020 / Published online: 5 January 2021

(c) The Author(s) 2021

\begin{abstract}
More and more European higher education students decide to take part in international student mobility (ISM). However, not much is known about the actual benefits of studying abroad. This paper assesses UK and Italian students' returns from ISM. Three research questions are addressed. First, does international student mobility increase graduates' employment probability and postgraduate study uptake? Second, do the returns to ISM differ according to the socio-economic background of graduates? Third, do the returns to ISM vary between two countries with contrasting labour market and education systems? Results, based on propensity score matching, indicate that mobility is positively associated with a higher employment probability. Mobility abroad is likewise linked with a higher likelihood of enrolling in postgraduate studies in Italy. The benefits of mobility in terms of employment do not differ significantly across socio-economic groups. However, mobility is particularly effective in boosting the uptake of postgraduate studies among mobile Italian graduates with a low socio-economic background. In Italy, ISM returns are substantially higher than in the UK, which could reflect that the skills accumulated and the signals sent to potential employers through ISM are greater in Italy.
\end{abstract}

Keywords International student mobility $\cdot$ Italy $\cdot$ Labour market outcomes $\cdot$ Mobility abroad $\cdot$ Propensity score matching $\cdot$ UK

\section{Introduction}

Policies fostering international student mobility (ISM), ${ }^{1}$ with ISM being defined as a period of learning abroad during enrolment in a higher education institution in the home country, aim to boost the interpersonal and cultural adaptation skills necessary to live in

\footnotetext{
1 For the rest of the paper, we will use the terms 'ISM', 'studying abroad' and 'student mobility' interchangeably.
}

Electronic supplementary material The online version of this article (https://doi.org/10.1007/s10734020-00631-1) contains supplementary material, which is available to authorized users.

Sylke V. Schnepf

sylke.schnepf@ec.europa.eu

1 European Commission, Joint Research Centre (JRC), Ispra, Italy 


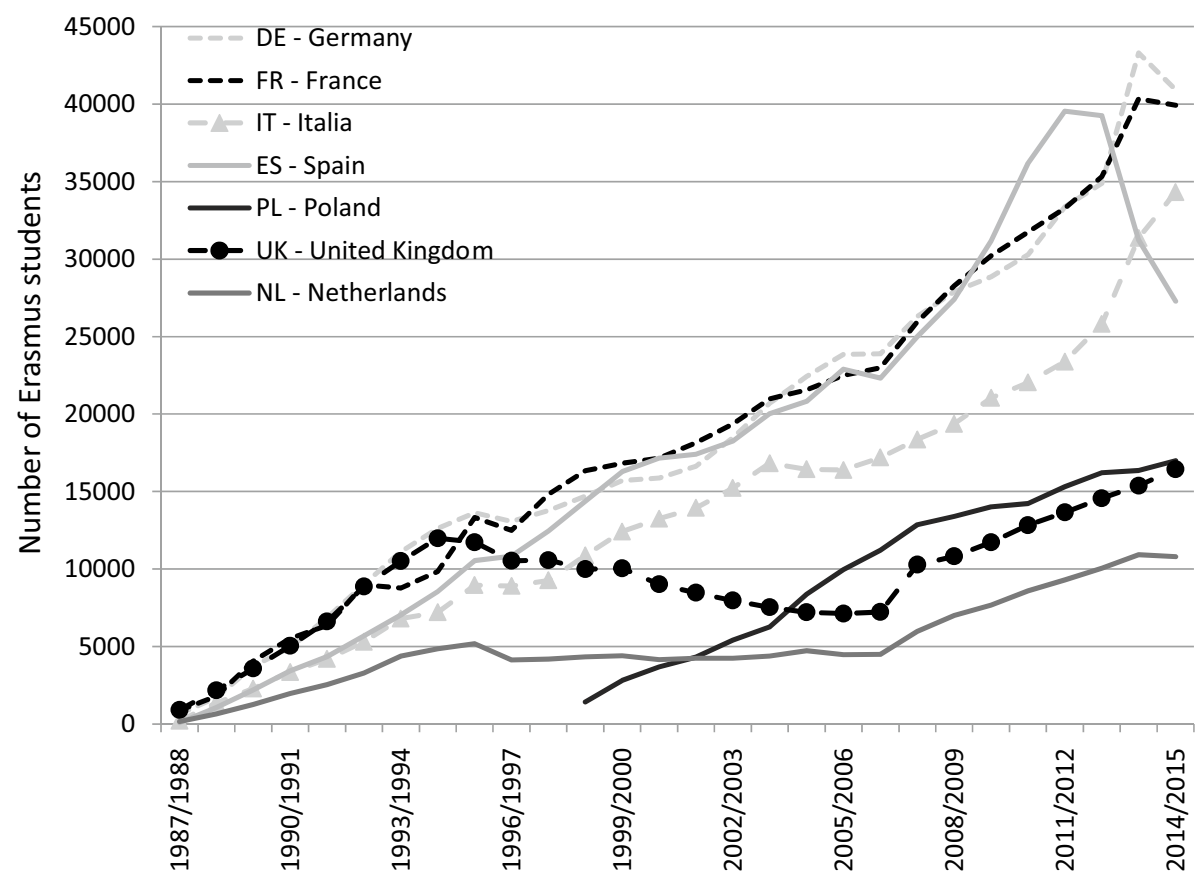

Fig. 1 Number of Erasmus students since 1987 by country

Source: Number of Erasmus students refers to mobilities in all tertiary programmes and derives from European Commission (2009, Annex 1; 2018, Annex 1)

multicultural and changing environments. Furthermore, ISM is often considered as a tool to enhance labour market prospects in globalised labour markets.

European ISM in the framework of Erasmus+, the main European Union programme for promoting student mobility, has risen from 3,000 in 1987 to over 300,000 today (European Commission 2009; European Commission 2018), a trend likely to continue in the future. Figure 1 shows the increase in Erasmus+ uptake since its creation for those seven EU countries with more than 10,000 students participating in Erasmus+ in 2014/2015. Italy has the third and the UK the sixth highest number of students across all European countries.

A recent European Commission report (2019, Fig. 37) suggests that Erasmus+ covers around $50 \%$ of all international student mobility in 28 European countries in 2017. In Italy, as many as $76 \%$ of ISM takes place in the framework of EU programmes, while this amounts to about $47 \%$ for the UK (Schnepf \& Colagrossi 2020).

Sociologists often examine student mobility in the context of social stratification in European societies. As students from higher social classes are more likely to participate in ISM (e.g. Hauschildt et al. 2015), better-off students might benefit more from the potentially positive outcomes associated with ISM opportunities than their less well-off counterparts. ${ }^{2}$

Although inequalities in opportunities for ISM uptake are important, inequalities in ISM-related outcomes are also central to comprehend the persistence of social inequalities

\footnotetext{
${ }^{2}$ In the following, students whose parents have a higher socio-economic background are defined as 'advantaged' and students whose parents have a lower socio-economic background are defined as 'disadvantaged'.
} 
across generations. The benefits of ISM may vary between participating students. If students with a higher socio-economic background benefit more from studying abroad, then student mobility might perpetuate already existing inequalities. The opposite may happen if the return to ISM is higher among lower social classes. Should the latter be true, this would be an important signal in favour of increasing the ISM uptake of students with a lower socio-economic background.

As such, it is surprising that the number of studies estimating the impact and possibly differential effects of studying abroad on students' further career decisions and labour market outcomes is rather limited (Di Pietro 2019). The reasons for this are twofold. First, measuring the impact of ISM implies being able to account for differences between ISM and nonISM students' intrinsic characteristics such as motivation and ability, which are associated with both future career progression and ISM participation. The literature taking this so-called selection bias into account is still circumscribed. ${ }^{3}$ This selection bias is likely to be greater for students with a lower socio-economic background, rendering the comparison of the returns across socio-economic groups even more problematic. Furthermore, the university of graduation matters both in terms of the supply of mobility grants (Schnepf \& Colagrossi 2020) and labour market outcomes (Britton et al. 2016). In very stratified higher education systems, student selection into universities can also serve as a proxy for possible unobservable variables that also guide mobility uptake. Graduate data often do not report the universities attended by the students. Such an omission can lead to biased estimates, especially when looking at the returns to ISM by socio-economic background. Second, existing studies tend to focus entirely on graduates entering the labour market, thereby leaving out mobile graduates who decide to take up postgraduate studies. As completion of the latter is associated with higher incomes in the long term, it is important to consider not only labour market outcomes but also career decisions after graduation when estimating the returns to ISM.

In this study, several of the challenges associated with the estimation of the effect of ISM on career decisions and progression are addressed. We focus on overall international student mobility (comprising Erasmus+ and other mobility programmes) and approximate (i) career decisions with graduates' decision to enrol in postgraduate studies and (ii) career progression with the employment probability at two points in time, so as to address the following research questions:

\section{Research question 1 Does ISM impact career decisions and progression?}

\section{Research question 2 Does ISM have a different impact according to socio-economic} class?

Most of the existing research is based on single-country data analysis. Therefore, it is difficult to say whether country contexts matter for graduates' returns to mobility. It is, however, very likely that ISM provides different signals in different labour market institution settings. To the knowledge of the authors, this has not been examined before. To reduce complexity, we have chosen two countries, the UK and Italy, that differ greatly in their higher education and labour market systems. This allows us to make assumptions regarding the signalling power of ISM according to the institutional setting, examining the following third research question:

\section{Research question 3 Do the returns to mobility differ between Italy and the UK?}

\footnotetext{
3 Important exceptions include, among others, Parey and Waldinger (2011), Rodrigues (2013), Di Pietro (2015), and Kratz and Netz (2018).
} 
The empirical analysis is based on propensity score matching and relies on two largescale graduate data sources.

\section{Theoretical considerations and literature review}

Student mobility is often perceived as a 'real world' learning environment encouraging students' personal exploration of different cultural and country settings (Amit 2010). Students participating in ISM generally report a high level of satisfaction with their experience abroad (Waibel et al. 2017). More importantly, studying abroad during tertiary education is expected to have an impact on a number of different graduate outcomes (Teichler 2017) ranging from study success, enhancement of competences (i.e. global mindedness; Roy et al. 2019), changes in values and attitudes (i.e. flexibility and cultural adaptation skills; Luo \& Jamieson-Drake 2015), and improved labour market prospects.

The present study focuses on two outcome variables that can be directly linked to future labour market incomes. First, we examine one element of career planning: graduates' decision to take up postgraduate studies. Students who enrol in postgraduate studies are often not included in any analyses that link social inequalities with ISM labour market returns since they are not in the labour force and, as such, are neither available for employment nor in receipt of income. The focus on uptake of postgraduate studies as an outcome variable is of importance since completion of further studies potentially increases students' human capital and thereby augments their earning potential in the long term (Roy et al. 2019). Second, we examine the returns to ISM in terms of employment, both shortly after graduation and in the medium term.

Returns to ISM regarding both of these outcomes may differ by graduates' socio-economic background, thereby increasing or decreasing societal inequalities.

\section{Studying abroad and employment status}

In the framework of human capital theory (Becker 1976), ISM can be regarded as an investment into human capital associated with costs and benefits. Student mobility takes place if individuals value the benefits higher than the costs. While students' key motivation for studying abroad is often to improve their language skills (Teichler 2017), ISM can also augment interpersonal skills (Roy et al. 2019) as well as enhance flexibility to work in different cultural environments and cross-cultural communication skills (Salisbury et al. 2013), all desirable competencies for working in globalised labour markets. The accumulation of these skills is likely to increase mobile students' chances of a successful entry into the labour market after graduation (Di Pietro 2015). ISM is also associated with investment into network development abroad and widening graduates' job search radius. This, however, might be at the cost of network loss in the home country (Wiers-Jenssen 2007). In addition, mobile students' improved skills could also raise their job expectations, which could result in higher reservation wages and longer time intervals for accepting job offers compared to non-mobile students. This could explain why ISM is associated with a longer time to find a first job in some European countries (Rodrigues 2013). 
The signalling theory (Spence 1973) suggests that educational choices, such as studying abroad, can serve as a signal that employers use to estimate individuals' productivity. ISM might reveal interpersonal skills, cross-cultural aptness, as well as other skills (discussed above) that are valuable in the labour market (Petzold 2017).

Both human capital and signalling theories suggest that ISM should positively affect labour market outcomes and hence the employment status of mobile students. Rational choice theory (see Breen \& Goldthorpe 1997) would predict that, in general, for students from a high socio-economic background, the benefits of studying abroad outweigh the relative cost of doing so (since they have funds, experiences and networks available), while this might be less often the case for their counterparts from a lower socio-economic background. This explains the difference in mobility uptake decisions between students with different socio-economic statuses (see, for instance, Netz \& Finger 2016). However, if ISM enhances the quality of the educational experience and, hence, compensates for limited school opportunities faced earlier in life, ISM schemes should especially benefit socio-economically disadvantaged graduates. This suggests that the returns to ISM should be higher for graduates with a lower socio-economic background.

Furthermore, well-off students are more likely to consider ISM as a means of 'self-realisation', i.e. a consumption good associated predominately with enjoyment, while for lessprivileged students, ISM should essentially be a human capital investment. In other words, the latter group of students is likely to opt for destination countries that will increase their labour market productivity (Waibel et al. 2017). Finally, returns to ISM could be higher for disadvantaged graduates given the higher relative costs of the signal provided by such an experience abroad compared to those for advantaged students (Netz \& Finger 2016; Spence 1973).

Evidence on this topic is rather limited (Bilecen \& Van Mol 2017), and the results of studies testing whether the effect of mobility varies across socio-economic groups are mixed. Di Pietro (2015) and Sorrenti (2017), using Italian data, conclude that mobility is more beneficial for disadvantaged students in terms of employment probability, whereas Netz and Grüttner (2020) find that German graduates with highly educated parents experience higher income returns than peers whose parents have a lower educational level.

\section{Studying abroad and career planning: uptake of postgraduate studies}

ISM can be interpreted as having an 'intrinsic formative value' (Amit 2010). The exposure of students to new cultural and social environments is expected to provide insight into different career opportunities, as well as to shape educational and professional aspirations (Roy et al. 2019). Studying abroad should raise awareness of educational options, help young students reflect and develop interests in specific future career directions, and hence contribute to making short- and long-term career plans that fit personal interests (Savickas et al. 2009; Kratz \& Netz 2018). Networking with students from different countries and university environments should also enhance the exchange on-and understanding of - future study opportunities after completion of one's first degree (Messer \& Wolter 2007). On top of this, the skills acquired during ISM as well as the signal sent by the decision to study abroad may well increase the probability of being selected into 
postgraduate programmes. ${ }^{4}$ This should further increase mobile graduates' uptake of postgraduate studies.

The increase in reflection and understanding of future career options and further study opportunities should be greater for students from a lower socio-economic background. According to Bourdieu and Passeron (1990), ${ }^{5}$ social capital is transmitted across generations and this partly explains why social classes are perpetuated over time. Therefore, individuals from the upper class are likely to have already benefited from international networks as well as career guidance and advice before taking part in ISM. While studying abroad can build up these networks further, the relative advantage that can be gained is likely to be larger for students endowed with lower social capital.

The discussion above leads to the formulation of the following two hypotheses:

Hypothesis 1 ISM increases the probability of being employed and of taking up postgraduate studies.

Hypothesis 2 The returns to ISM are expected to be larger among low socio-economic status students compared to their better-off counterparts, especially in terms of the uptake of postgraduate studies.

\section{How do Italy and the UK compare?}

Returns to study-related stays abroad are likely to be heterogeneous in the European Union since education supply and labour market demand for ISM students vary across countries (Jacob et al. 2019). With the exception of two cross-country studies (Jacob et al. 2019; Rodrigues 2013), existing research generally focuses only on one single country, so that it is difficult to say whether country-specific findings have relevance beyond the country examined. For this study, the choice of the UK and Italy derives from the stark contrast in their education systems and labour markets. The higher education sector in the UK is much more stratified than in Italy, with students from higher socio-economic backgrounds being overrepresented in prestigious universities. This can be explained by the English marketoriented higher education model where access to more prestigious university is often conditional on outstanding achievement results in upper secondary school exams, successfully passed entry tests and willingness to pay higher student fees (Dobbins and Knill 2014). While students can cover these fees with student loans, Mouline et al. (2016) show that poorer students generally hesitate more to indebt themselves and hence are more likely to opt for less prestigious and more affordable programmes and universities. Not surprisingly, the UK displays the greatest association between parental education and the probability of graduating from a top institution among eleven European countries, while Italy ranks eighth (Triventi 2013).

\footnotetext{
4 The composition of students holding a master's degree with respect to those continuing on to pursue doctoral studies might differ, as well as the effect of ISM on these two categories of students.

5 We acknowledge that Coleman (1988) is generally more closely associated with the notion of 'social capital' than Bourdieu. However, our present argument emphasises the unequal positions of different individuals in the social structure, which is a perspective generally closely linked to Bourdieu.
} 
Traditionally in Italy, universities did not select students by requesting good results in upper-secondary leaving exams (maturità), numeri clausi or university entry tests. ${ }^{6}$ Progressively, with the increased autonomy of universities, admission to first-cycle degrees has become more university-specific, with each university defining the access conditions and possibly enforcing some restrictions such as numerus clausi, assessment tests or admission requirements. Yet, Italian universities have not yet taken on the market model. They are less hierarchically classified according to their prestige and quality than UK universities. In addition, Italian university fees are moderate compared to those in England.

Graduates' access to jobs is a function of both the demand and supply of the labour market. Although the supply of graduates is lower in Italy than in the UK, ${ }^{7}$ the Italian labour market is relatively rigid. According to the OECD indicator on the 'Protection of permanent workers against individual and collective dismissals', Italy scores highest together with Belgium and the Netherlands among 21 European countries covered in the dataset, while protection is the lowest in the UK (OECD 2017). At the same time, unemployment, especially among young people aged below 25, was (and still is) higher in Italy (around $29 \%$ ) than in the UK (around 21\%) for 2011, the year of graduation covered with our data (Eurostat 2018). The lower flexibility of labour markets makes the transition from tertiary education to work more difficult for Italian than for UK students.

In this context, the signal of studying abroad might be more relevant in Italy. The vertical and horizontal stratification of the UK university system ensures that the university diploma provides a clear signal to employers about graduates' skills. This might be less the case in Italy, where ISM could serve as a means to differentiate students and signal relevant skills for the labour market. As discussed earlier, this includes, among other things, language skills and the flexibility to work in multicultural and changing environments. According to Sorrenti (2017), in Italy, where language proficiency is rather low, ISM often constitutes a unique opportunity to acquire such skills. In addition, UK students already speak the lingua franca. Therefore, the labour market returns associated with ISM are likely to be greater for Italian than UK students. Along this line, Van Mol (2017) reports that Italian employers value experience abroad more than those from the UK, with about one third of employers in Italy agreeing that studying abroad is important compared to just $10 \%$ in the UK.

Similar hypotheses apply for the uptake of postgraduate studies. In the UK, a graduate's signalling power as well as any decision related to pursuing additional studies after graduation are, to a large extent, predetermined by the prestige associated with the university attended. The ISM experience is hence unlikely to centre on reflection and the understanding of future career options or to substantially facilitate the access to postgraduate programs. In contrast, in Italy, graduates need to develop strategies to differentiate themselves from other graduates. ISM could help do so with the mechanisms described earlier.

Hypothesis 3 Mobility has greater returns in Italy than in the UK both in terms of employment probability and the uptake of postgraduate studies.

\footnotetext{
${ }^{6}$ Exceptions include studies of medicine, veterinary, dentistry, architecture and degrees in health and education sciences, as well as private tertiary education institutions where access is restricted.

7 Higher education enrolment covers one fifth of young people in Italy compared to almost half in the UK (Eurostat 2017).
} 


\section{Data and methodology}

\section{Data}

UK data derive from the merged graduate population and survey data of the UK Higher Education Statistics Agency (HESA). The Italian data stem from graduate surveys of graduates and postgraduates conducted by the Italian National Institute of Statistics (ISTAT). For the UK and Italy, only students graduating with their first higher education degree in 2011 are considered for the analysis.

\section{UK dataset}

HESA (HESA Student Record 2010/11) covers information on the entire population of students registered in UK higher education institutes each year ('HESA Student Record Data'). For the purpose of this paper, HESA extracted the population of all UK-domiciled, full-time, first-degree graduates studying a degree with an expected length of study of at least 3 years, excluding graduates who were not in the same course at the same higher education provider in the 2 years prior to their graduation year. This extraction covers around $70 \%$ of the entire population of all graduates.

From the population of graduates, data were drawn with a response rate of around $80 \% 6$ months after graduation, comprising around 118,000 graduates from 136 universities (after exclusions; see below). Respondents to the survey entitled 'HESA Destinations of Leavers from Higher Education Record' were then again contacted 3 years after graduation, resulting in around 25,000 responding graduates from 135 universities. For the latter survey, called 'HESA Destinations of Leavers from Higher Education Longitudinal Record', the response rate was low at 20\%. This low response is similar to other graduate surveys like those conducted in Germany and Hungary. However, given this low unit-response to the UK survey conducted 3 years after graduation, weighting is applied, which can to some extent but unlikely fully solve the problem of non-response bias normally associated with low response.

\section{Italian dataset}

ISTAT data stem from the population of students who graduated from Italian universities in 2011, i.e. 299,499 individuals having studied in 90 universities. Around $57 \%$ of the student population comprised first-degree graduates, $29 \%$ were postgraduates, whilst the remaining $14 \%$ were graduates from a 'unique cycle'. In 2015, 4 years after graduation, around $20 \%$ of the 2011 cohort of students was interviewed. The sample design is stratified along universities, gender, and type of subject studied. The overall student response rate for this survey is high compared to other existing graduate surveys, at around $70 \%$. The empirical analysis below focuses on the roughly 20,000 first-degree graduates only, i.e. students who completed a first degree officially lasting 3 years (socalled Laurea triennale). As for the UK, students who changed university during the course of their studies are excluded from the sample. 


\section{Item non-response}

In the UK, the item non-response rate for parental education, the socio-economic background proxy measured in the same way for both countries, amounts to $30 \%$. These students are not taken into account for the main analyses. However, we show that UK results are robust to item non-response, since results using another socio-economic background measure, parental occupation, ${ }^{8}$ are very similar. Upper secondary school degree information is also not available for $17 \%$ of students. For these students, the average is imputed and an additional dummy created that is set to 1 for imputation and 0 otherwise. Robustness checks show, however, that if the individuals with this missing information are excluded from the sample, results remain similar (Table A6 in the Appendix). Other items have a non-response of less than $1 \%$.

For the Italian data, item non-response is low for all variables used in the analyses.

\section{Causality and empirical approach}

Measuring the impact of studying abroad implies taking into account the fact that students who opt for an exchange semester generally differ from non-mobile students in terms of intrinsic characteristics such as motivation, ability, and socio-economic background. If this so-called 'selection bias' is ignored, the association between mobility uptake and any ISM outcome could simply be due to the different characteristics of mobile and non-mobile students and not to the consequence of ISM per se.

Differences in these unobservable characteristics might not exist only between but also within socio-economic groups. In line with Bourdieu's notion of social capital theory (Bourdieu \& Passeron 1990), underprivileged students might evaluate studying abroad as less beneficial (Loerz et al. 2016; Salisbury et al. 2008), perceive finances and separation from family as much more pressing (Orr et al. 2011), and have lower language skills (Loerz et al. 2016) than privileged students. Therefore, disadvantaged students who still decide to participate in ISM might need to overcome very high obstacles. Only disadvantaged students with very specific characteristics might be able to do so. As a consequence, disadvantaged ISM students might differ substantially from other disadvantaged non-ISM students. It might well be that their differences cannot be captured well with observable variables. In addition, advantaged ISM and non-ISM students are less likely to differ, given that their obstacles for taking part in mobility is lower. As a consequence, we expect any possible bias in our measurement to be higher for the group of disadvantaged students than for the group of advantaged students.

The richness of both the UK and Italian datasets allows us to account for selection bias conditioning on differences between mobile and non-mobile students in terms of sociodemographic characteristics, upper secondary school performance, university attended, and the selected field of study. All of these variables are likely to be associated with a mobility decision and the outcome variables under scrutiny.

This study employs propensity score matching (PSM) to estimate the causal effect of ISM. Matching procedures assume that the selection bias is based on observable characteristics and consists in comparing the outcome variables $Y i$ between graduates with and

\footnotetext{
8 This variable displays a slightly lower non-response rate $(20 \%)$, while both parental education and occupation data are missing for only $8 \%$ of the entire sample.
} 
without study abroad experience who are as similar as possible along the n-dimensional vector of the pre-treatment characteristics $X i$. Directly matching the vector of covariates $X i$ would be computationally demanding, especially when the number of covariates is large. PSM consists of summarising $X i$ with a single variable, the propensity score $P(X i)=\mathrm{P}(\mathrm{PSM}=1 / X i)$, i.e. the probability of studying abroad given the set of covariates $X i$.

The advantages of PSM as compared to regression analysis are that it is non-parametric, relaxes any linearity assumption, and restricts the analysis to samples of ISM and non-ISM students with similar propensity scores (common support condition). Similar to regression analysis, the validity of the PSM identification strategy rests on the assumption that, conditional on $\mathrm{Xi}$, the exposure to ISM is random. This is the so-called conditional independence assumption (CIA). Such a PSM approach is justified in our context because both Italian and UK data provide information on the family background, the upper secondary school exams and the university attended by the graduate students. Hence, any omitted variable bias should be small, as the graduates' unobservable characteristics potentially correlated with both $Y i$ and ISM uptake should be proxied to some extent by the vector of variables $X i$. Nevertheless, we are careful in claiming a clear causal link between ISM and $Y i$, especially once students from more disadvantaged backgrounds are concerned (as discussed above).

\section{Outcome variables}

The first outcome captures graduate employment status at two different points in time. For Italy, the employment status is measured 1 and 4 years after graduation, and for the UK, after 6 months and 3 years. ${ }^{9}$ The employment status measure takes a value of 1 if the student is employed and 0 if unemployed. Individuals not participating in the labour market (since, e.g. they are enrolled in education) are excluded from this analysis.

The second outcome is the uptake of postgraduate studies. The dummy variable is equal to 1 if the respondent enrolled in postgraduate studies. In the UK, the variable identifies those enrolled in postgraduate education 6 months after graduation. The comparison group includes all those who are not in education 6 months after graduation. In Italy, the variable identifies those who enrolled in postgraduate education at any time in the 4 years after graduation. Hence, the comparison group includes all those who never enrolled in further studies (independent of their employment status 4 years after graduation). Given differences in the measurement (a 4-year vs. a 6-month interval) of postgraduate uptake, we expect postgraduate uptake to be higher in Italy. This is discussed further in the next section.

More details on the definitions of variables by dataset are provided below and in the Appendix (Table A1).

\footnotetext{
${ }_{9}$ In the case of Italy, respondents are asked four years after graduation about their labour market status one year after finishing undergraduate studies. In contrast, in the UK the employment status is recorded separately through the two surveys described earlier.
} 


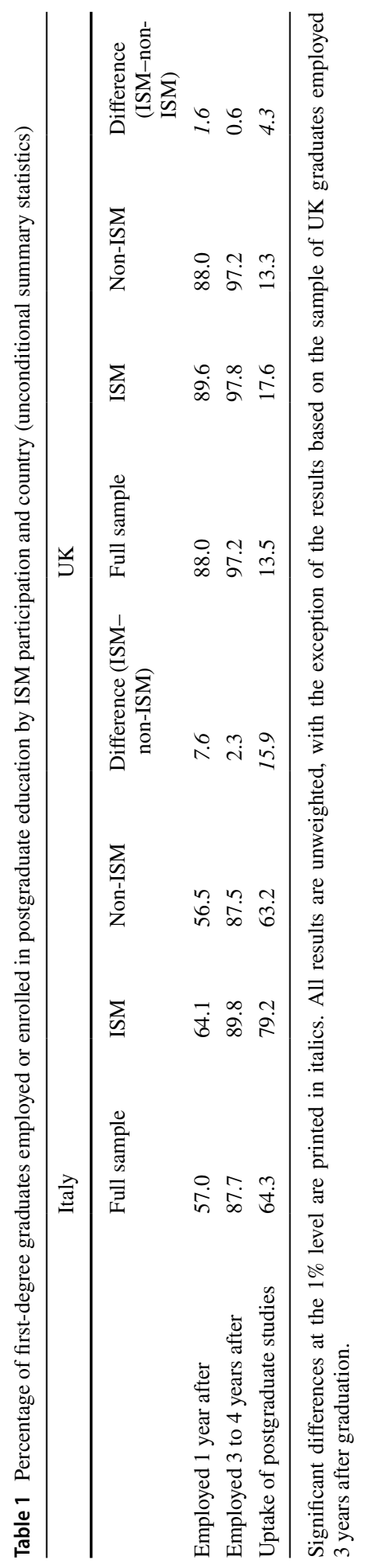




\section{Identification strategy and control variables}

The Italian and UK data cover a large set of covariates $X i$ that we use in the matching procedure. The socio-demographic characteristics covered with $X i$ include the age, gender, and citizenship (the latter only for Italy) of the graduates as well as the regional location of residence. $X i$ also includes information on upper secondary school leaving results. This should allow us to control for $Y i$ variations between ISM and non-ISM students driven by differences across students in human capital accumulation before the treatment. For Italy, we include a variable indicating the score obtained at the maturità, the upper secondary school leaving exam (ranging between 60 and 101), as well as indicators for the type of high school attended (technical, scientific, classical or linguistic). For the UK, ability is captured by the number of and mark for upper secondary school leaving results (generally called 'A-levels'). $X i$ also accounts for the field of study and the university attended by the graduates. Students are spread across 14 fields and 80 universities in Italy and 20 fields and 136 universities in the UK. Finally, the family background of the graduates is measured by an indicator equal to 1 if at least one of the parents has achieved tertiary education and 0 otherwise.

\section{Results}

\section{Summary statistics}

\section{Employment status and postgraduate studies: UK versus Italy}

The summary statistics reported in Table 1 suggest that 1 year after graduation, $57 \%$ of first-degree graduates in Italy are employed compared to $88 \%$ of those from the UK. Three years after graduation, the difference in the employment rates between Italian and UK graduates decreases but remains substantial, with $88 \%$ compared to $97 \%$. The considerable difference between the two countries is in line with official statistics. In 2011, the UK displayed one of the highest employment rates for 25- to 34-year-old tertiary educated individuals $(88 \%)$ across OECD countries, while only $67 \%$ of Italian graduates were employed (OECD 2020). The limited demand for workers with academic-oriented qualifications as well as the effect of the Great Recession partly explain the low employment rate of tertiary graduates.

Our indicator of postgraduate studies uptake indicates that the proportion of students enrolling in postgraduate studies is much higher in Italy than in the UK (64\% versus 14\%, respectively, in Italy and the UK). There are several reasons for this. First, as described earlier, the measures for the uptake of postgraduate studies differ between the two countries. In Italy, enrolment in postgraduate studies is taken into account up to 4 years after completion of tertiary first-cycle degrees, while for the UK, this information is observed only up to 6 months after graduation. This implies that this variable underestimates the share of students enrolling in postgraduate studies in the UK. Second, official statistics show that whereas in $2014^{10}$ only $34 \%$ of Italian young adults were expected to graduate from tertiary education (against $54 \%$ in the UK), $20 \%$ of them were expected to earn a postgraduate degree,

$\overline{10} 2014$ is the closest year to 2011 for which we could find official statistics on this topic. 


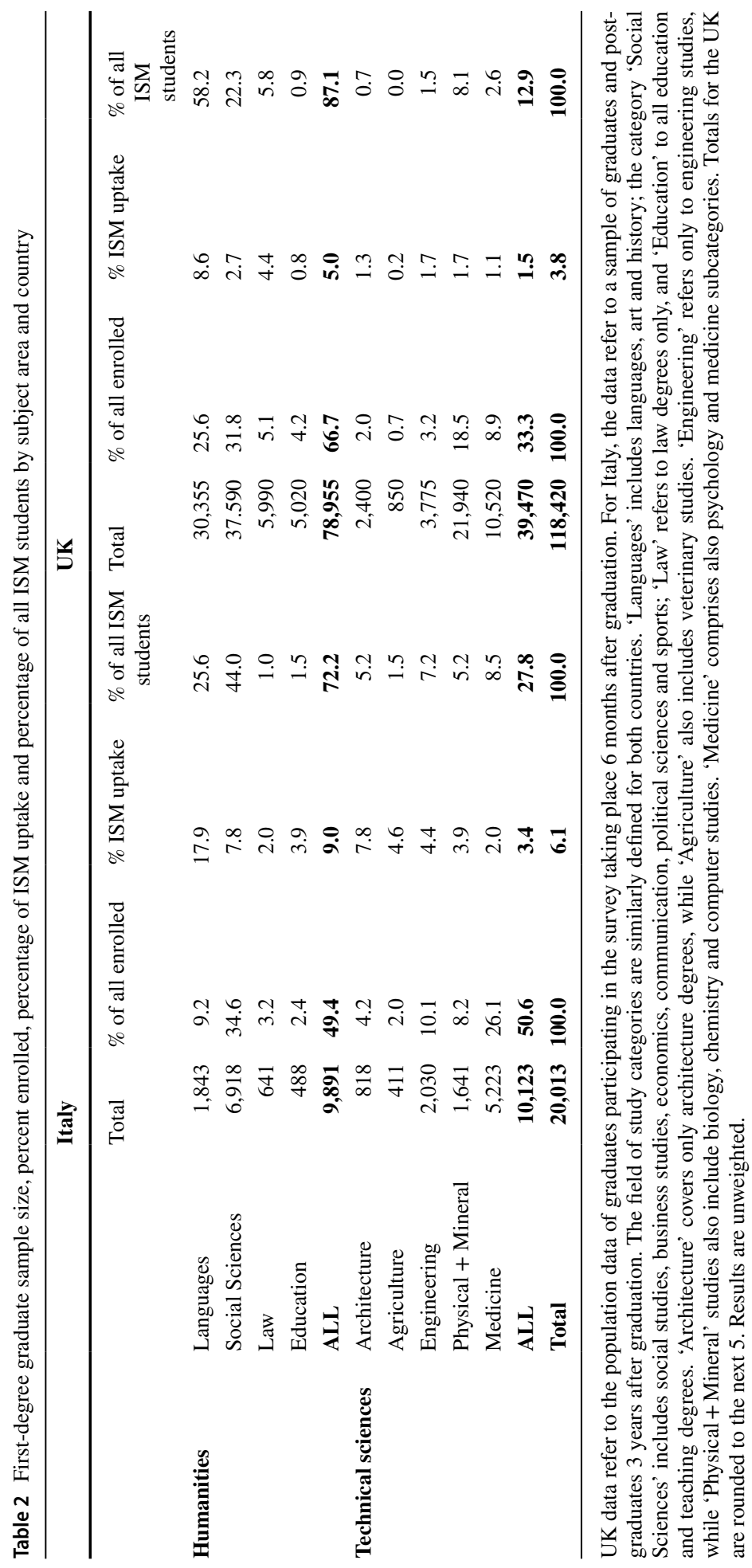


Table 3 Individual characteristics by ISM participation and country

\begin{tabular}{|c|c|c|c|c|c|c|}
\hline & \multicolumn{3}{|l|}{ Italy } & \multicolumn{3}{|l|}{ UK } \\
\hline & ISM & Non-ISM & Difference & ISM & Non-ISM & Difference \\
\hline \multicolumn{7}{|l|}{ Socio-demographic (\%) } \\
\hline Female & 60.4 & 57.8 & 2.7 & 65.0 & 58.3 & 6.7 \\
\hline Italian & 98.8 & 99.3 & -0.5 & na & na & na \\
\hline Age $\leq 22$ & 35.0 & 26.6 & 8.4 & 92.6 & 86.3 & 6.3 \\
\hline Age $23+24$ & 54.2 & 50.8 & 3.4 & 4.0 & 4.7 & -0.7 \\
\hline Age $25-29$ & 9.6 & 14.9 & -5.3 & 2.4 & 4.0 & -1.6 \\
\hline Age $30+$ & 1.2 & 7.7 & -6.5 & 1.1 & 5.0 & -3.9 \\
\hline $\begin{array}{l}\text { Both parents not having completed tertiary } \\
\text { education }\end{array}$ & 62.2 & 76.3 & -14.1 & 34.0 & 46.2 & -12.2 \\
\hline \multicolumn{7}{|l|}{ Regional location } \\
\hline Northwest (IT)/Scotland (UK) & 29.6 & 27.9 & 1.7 & 13.8 & 8.4 & 5.4 \\
\hline Northeast (IT)/Wales (UK) & 27.5 & 21.8 & 5.7 & 0.6 & 4.8 & -4.2 \\
\hline Central (IT)/Northern Ireland (UK) & 18.9 & 19.2 & -0.3 & 0.5 & 1.4 & -0.9 \\
\hline South (IT)/England (UK) & 15.9 & 21.9 & -6.0 & 85.1 & 85.4 & -0.3 \\
\hline Insular (IT)/ & 8.1 & 9.2 & -1.1 & na & na & na \\
\hline \multicolumn{7}{|l|}{ Upper secondary school results } \\
\hline$\%$ having no A grade & na & na & na & 31.4 & 47.7 & -16.3 \\
\hline$\%$ less than 3 A-levels & na & na & na & 6.0 & 13.0 & -7.0 \\
\hline High school leaving grade & 83.8 & 81.9 & 1.9 & na & na & na \\
\hline$\%$ attending general upper secondary & 73.8 & 58.3 & 15.0 & na & na & na \\
\hline Ability missing & na & na & na & 9.4 & 17.7 & -8.3 \\
\hline
\end{tabular}

The table shows the percentage of individual characteristics by group. For example, $60.4 \%$ of Italian ISM graduates are females. Significant differences at the $1 \%$ level are printed in italics. For the UK, results are presented for the 118,420 graduates taking part in the 6 months postgraduation survey. For Italy, the statistics are based on 20,013 students. All results are unweighted. na stands for 'not available'.

compared to only $17 \%$ in the UK. In other words, Italy combines low tertiary graduation rates with high postgraduate uptake rates for first-cycle programmes (OECD 2015). The opposite is found in the UK. The fact that the majority of Italian students with a first-cycle degree enrol in postgraduate studies, without necessarily completing it, has often been partly attributed to the difficulty of finding a job after graduation. Enrolling in postgraduate studies while simultaneously looking for a job could be a better 'job market ticket relative to that of being unemployed' (Dornbusch et al. 2000, p.11). These differences between the UK and Italy do not impede our identification strategy as long as mobile and non-mobile students in each country are not affected differently.

\section{Who are the mobile in Italy and the UK?}

The unconditional summary statistics displayed in Table 2 show the pattern of ISM participation in the two countries. Engagement in ISM for first-degree graduates is smaller in the UK, with $4 \%$, compared to Italy with $6 \%$. In the UK, $58 \%$ of all ISM students study languages, in contrast to $26 \%$ in Italy. The predominant portion of UK ISM students graduate in humanities subjects. Only about every tenth ISM graduate completes a degree in 
technical science subjects (such as architecture, engineering, physics, etc.). In Italy, this share is much higher, with every fourth student obtaining a degree in a technical subject.

As discussed earlier, any analysis examining the impact of ISM needs to address the potential selection bias, i.e. the fact that mobile and non-mobile students differ in their characteristics (see Table 3). In both countries, individuals with a low socio-economic background are less likely to engage in ISM. This trend is pronounced for Italian graduates, where on average, $76 \%$ of non-ISM students have two parents who did not complete tertiary education, compared to just $62 \%$ of ISM students. In addition, in the UK, almost half of non-ISM students did not achieve the highest mark of A for any of their A-levels, compared to less than a third for ISM students. The non-mobile students are also more likely to not have successfully completed three A-level exams. The same pattern is found for Italy, where non-ISM students' average scores in the high school leaving exam are lower than those obtained by ISM students. In sum, in both countries ISM students are positively selected, having more favourable characteristics for employment chances and postgraduate enrolment probability.

The distribution of mobile students across universities is also highly positively skewed (results not shown). In Italy, 6 out of 80 universities do not have any students studying abroad, while $11 \%$ of universities have more than $15 \%$ of ISM students. The picture is similar for the UK: 29 out of 136 universities do not have any students with ISM experience. At the 90th percentile of the university distribution, almost $10 \%$ of students study abroad. Given this considerable difference in ISM uptake between universities, the modelling needs to take into account the particular universities students are enrolled in.

\section{How do students studying abroad fare compared to the non-mobile?}

If we do not take the positive selection of ISM students into account, how do the outcomes $Y i$ compare between those who did and did not study abroad?

Table 1 displays summary statistics of the outcome variables by treatment status and country. In the UK, the employment probability of mobile students is slightly but significantly higher 1 year after graduation and not significantly different 3 years after graduation, compared to non-ISM students. In Italy, students studying abroad are almost 8 percentage points more likely to be employed 1 year after graduation and 2 percentage points 4 years after graduation. Once the focus is on uptake of postgraduate studies, ISM students are, in both countries, significantly and sizably more likely to decide to pursue further education.

These results could be either due to selection bias or due to ISM influencing both employability and postgraduate study uptake. As students studying abroad are positively selected, the figures reported in Table 1 should be the upper bound values of the actual effect of ISM. The next section discusses the PSM results, once the selection bias is taken into account.

\section{Impact of ISM-results of propensity score matching}

\section{Matching ISM and non-ISM students}

Probit models are employed to estimate the propensity scores of participation in ISM programmes. Table A2 in the Appendix displays the corresponding marginal effects. A general way of assessing the quality of the matching is to examine the balance of the covariates between the ISM and non-ISM matched graduates. To do this, we compute the 
Table 4 Percentage-point differences between ISM and non-ISM graduates in the probability to be employed and the uptake of postgraduate studies (propensity-score-matching-based estimates using Epanechnikov kernel matching)

\begin{tabular}{|c|c|c|c|c|c|}
\hline & \multicolumn{2}{|l|}{ Italy } & \multicolumn{2}{|l|}{ UK } \\
\hline & & Percentage points & se & Percentage points & se \\
\hline \multirow[t]{3}{*}{ Employed 1 year after graduation } & Low SES & $5.6^{*}$ & 2.9 & 2.4 & 2.6 \\
\hline & High SES & 7.9 & 4.9 & 1.9 & 1.7 \\
\hline & All & $6.3 *$ & 2.3 & $2.3^{*}$ & 1.1 \\
\hline \multirow[t]{3}{*}{ Employed 3 to 4 years after graduation } & Low SES & $3.3 *$ & 1.3 & 2.0 & 2.7 \\
\hline & High SES & 3.7 & 2.1 & 3.2 & 2.1 \\
\hline & All & $3.6^{*}$ & 1.2 & 2.3 & 1.5 \\
\hline \multirow[t]{3}{*}{ Uptake of postgraduate studies } & Low SES & $10.8 *$ & 1.6 & 1.9 & 1.8 \\
\hline & High SES & $4.8^{*}$ & 1.7 & -0.2 & 1.7 \\
\hline & All & $8.3 *$ & 1.0 & 0.9 & 1.1 \\
\hline
\end{tabular}

Significant differences at the 5\% level are printed in italics and indicated by '*' and at the $10 \%$ level are printed in italics. Standard errors are bootstrapped (200 replications for Italy and 50 for the UK). Universities without any mobile students are excluded from the analysis. SES stands for socio-economic status and se for standard errors. Students are defined as having a low SES if neither of their parents hold tertiary education. Covariates used for the estimation of the propensity scores include age, gender, citizenship (only for Italy), parental education (when the estimation is for the entire sample), information on upper secondary school performance, indicators for the type of high school attended (only for Italy), the university attended, the field of study, as well as the region of residence (see Table A1 for more information). For the UK, the sample size is based on 83,145 students for employment 6 months after graduation, 19,845 students for 3 years after graduation, and 108,690 students for postgraduate study uptake. For Italy, the corresponding sample sizes are $8891,16,586$ and 19,806.

standardised bias, i.e. the difference in means of the covariates between ISM and matched non-ISM graduates, divided by the standard deviation (Rosenbaum \& Rubin 1985). Tables $\mathrm{A} 7 \mathrm{a}$ and $\mathrm{A} 7 \mathrm{~b}$ as well as Figures A1 and A2 in the Appendix display the percentage of standardised bias by covariate for both the raw and matched samples. The empirical literature generally assumes a mean standardised bias of 5\% after matching to be reasonable (Caliendo \& Kopeining 2008, p. 48). For both countries, once the sample is matched, the mean of the standardised biases are below this threshold. In addition, the pseudo $R^{2}$, which indicates the covariates' power to determine the probability of participating in ISM after controlling for the propensity score, is close to zero.

Comparing the probability of employment and uptake of postgraduate studies between Tables 1 and 4, differences between ISM and non-ISM graduates generally decrease, reflecting the positive selection into mobility. A notable exception is the slight but significant increase in employment probability 4 years after graduation in Italy.

\section{Does ISM have a positive effect on employment and postgraduate study uptake in Italy and the UK? (Hypothesis 1)}

Turning to the PSM estimates, Table 4 displays the percentage-point difference in the outcome under scrutiny between ISM and non-ISM graduates. We report the 'average treatment effect on the treated' (ATT) for each of the outcome variables by country and 
students' socio-economic status. Epanechnikov kernel-matching algorithms are used for the matching procedure, and bootstrapped standard errors are reported.

Out of six PSM estimates, based on the full sample of graduates, the return to mobility is positive and significant for four model specifications. About 1 year after graduation, ISM increases employability by 6.3 percentage points in Italy and 2.3 percentage points in the UK. The long-term effect of mobility is lower, however, with an employment advantage of 3.6 percentage points in Italy after 4 years and no significant benefit in the UK 3 years after graduation. This indicates that ISM acts as a strong positive signal for recruiting graduates into first employment (Petzold 2017), but over time other signals or human-capitalenhancing experiences, such as first employment experiences after graduation, gain greater importance for future employment recruitment.

Italian ISM students are also 8.3 percentage points more likely to have enrolled in postgraduate studies after the completion of the triennale than non-ISM students. This result is in line with the theoretical assumptions. Both signalling and human capital theories suggest that ISM should increase the probability of being successful if applying for postgraduate programmes. Studying abroad fosters an awareness of educational options as well as the benefits associated with further studies for future labour market outcomes. This might especially have been the case for young Italian students given the strong effect the Great Recession had on the Italian labour market.

However, in the UK mobility is not significantly linked with further study. This suggests, in line with the theory, that the signal of studying abroad is more relevant in Italy than in the UK. Given the high stratification of the UK educational system, students can achieve an impressive curriculum vitae if they choose and can attend prestigious universities and study programmes. As a consequence, for UK students the experience abroad is likely to be less valuable in terms of a signal. Furthermore, given the international orientation of the UK higher education system, employers might perceive that students' gain less with international student mobility. In the UK, employment chances after graduation are also much higher than in Italy, so that ISM students in the UK are less likely to exploit the knowledge and experiences gained abroad for future career moves than those from Italy.

\section{Are the returns to mobility heterogeneous across socio-economic groups? (Hypothesis 2)}

Neither in the UK nor in Italy are the employment returns significantly different across the two socio-economic groups of students. In Italy, results generally suggest that the returns to ISM are higher for students from higher socio-economic backgrounds. Nevertheless, these variations across socio-economic groups in the returns to ISM are not significantly different from zero. A similar pattern appears for the UK.

However, once the focus is on postgraduate study uptake, the picture changes. In the UK, the uptake of postgraduate studies does not differ by socio-economic background when the latter is proxied by parental education (Table 4). Yet, if family background is measured by parental occupation (Appendix Table 3), ISM students are 3.3 percentage points more likely to take up further studies than their non-ISM peers among the group of graduates whose parents are not working in professional occupations. In contrast, among students whose parents hold professional occupations, participation in ISM is not associated with higher postgraduate study uptake. For Italy, results are consistent for both socioeconomic background measures. Disadvantaged ISM graduates have a higher uptake of postgraduate studies of between 11 and 12 percentage points compared to their non-ISM 
peers. In contrast, for graduates who have grown up in a highly educated family environment, the difference amounts to 'just' 5 or 6 percentage points. The difference in the returns between both groups is significant at the $1 \%$ level. Engaging in ISM might therefore compensate for a possible earlier disadvantage faced by students with a lower parental socio-economic background, as it allows them to increase their chance of gaining higher education credentials. ISM should thus decrease social inequalities through its effect of increasing postgraduate study completion, especially for disadvantaged students in the long term (as discussed above).

\section{Are the returns to ISM higher in Italy than in the UK? (Hypothesis 3)}

As discussed earlier, the rigidness of the Italian labour market compared to that of the UK, the high appreciation of ISM by Italian employers, and the characteristics of the educational systems of both countries led us to assume that the returns to mobility should be higher for Italian than for UK graduates. Our results confirm this expectation. In the short run, ISM is associated with a 6.3 percentage point increase in employment probability in Italy but just a 2.3 percentage-point increase in the UK. If we focus on the percent increase, and hence link this result back to Table 1, mobility increases employment probability by $11 \%$ (6.3 percentage points expressed as a percentage of 57\%) in Italy and 3\% in the UK. In the medium term, in Italy, the effect of ISM more than halves compared to what we observe 1 year after graduation. The return to mobility remains, however, almost two times bigger in this country than in the UK. ${ }^{11}$ Similarly, studying abroad increases the uptake of postgraduate studies by 8 percentage points, while there is no significant association in the UK.

\section{Are the results robust to alternative specifications?}

Table 4 in the Appendix shows that results are similar if caliper instead of kernel matching is used to estimate the returns to ISM. Furthermore, Table 3 in the Appendix, which provides estimates based on parental occupation instead of parental education as proxy for socio-economic background, indicates that results are generally robust to the choice of socio-economic background measure. Since $92 \%$ of respondents answer at least one of the two parental background questions, similar results with different measures also indicate that item non-response is unlikely to drive the results found. The only exception is for the estimated effect of postgraduate study uptake in the UK, which is significantly higher for disadvantaged ISM students compared to non-ISM peers when the socio-economic background is measured by parental occupation.

The estimates for the calculation of the propensity scores include information on the particular universities attended by students. Above, it was argued that this information is often not taken into account in existing studies, even though different universities have varying success in securing ISM grants and ensuring a smooth insertion of their students into the labour market. Furthermore, information on universities can proxy other unobservable characteristics associated with both mobility uptake and outcomes. Table A5 in the Appendix unveils how the results are affected if university fixed effects are not included when estimating the propensity scores. While the estimates remain similar for Italy, with the

${ }^{11}$ The percent increase in employment is equal to $2.4 \%$ and $4.1 \%$, respectively, in the UK and Italy. 
highly segregated higher education system in the UK, the exclusion of universities would clearly affect the conclusions. Indeed, when the matching procedure does not account for the university attended, students with a lower socio-economic background benefit more from mobility than those with a more favourable family background, this being true both in terms of uptake of postgraduate studies and employment status 6 months after graduation. Such a finding confirms that the selection bias into mobility is more salient among students with a poor family background compared to peers coming from more privileged families. University fixed effects capture the disadvantaged students' unobservable characteristics that allow them to overcome the hurdles their social group faces when attending highly prestigious universities. This can also be shown with access rates to higher-ranked universities: only $21 \%$ of disadvantaged non-ISM students, compared to $52 \%$ of disadvantaged ISM students, manage to enrol in prestigious Russell universities, reflecting a 31 percentage-point difference. In the group of advantaged students, this gap represents a 25 percentage-point difference and is, therefore, $20 \%$ smaller.

\section{Conclusions}

ISM is expected to enhance, among other things, labour market prospects in globalised labour markets. European ISM has been increasing consistently over the last 30 years. The purpose of this study was to assess possible ISM returns in terms of (i) employment status at two different points in time and (ii) uptake of postgraduate studies in Italy and the UK. The study applied propensity score matching to account for selection bias and employed graduate survey data with rich information on auxiliary variables. Unusual for these kinds of surveys, the datasets also include information on the universities attended by graduates.

Results suggest that especially in countries with highly stratified tertiary education systems like the UK, any kind of causal impact evaluation of ISM should consider information on universities attended since otherwise, the effects of ISM-especially for students with lower socio-economic background - could be substantially overestimated.

The limitations of this study include the following. First, the consistency of our estimates depends on the validity of the conditional independence assumption. Therefore, it is still possible to have omitted relevant covariates simultaneously correlated with ISM and the outcome variables. Second, for the UK data, item non-response is high for graduates' socio-economic status and upper secondary school results. Yet, robustness checks indicate that this is unlikely to influence results. Third, this study is based on slightly different timeframes of survey collection. These are problems common in cross-national studies using graduate survey data given the current lack of Europe-wide comparable data.

Results indicate that ISM participation improves employment probability, at least in the short term. Italian ISM graduates are 6.3 percentage points more likely to be employed than their counterparts roughly 1 year after graduation, and in the UK mobile students are 2.3 percentage points more likely to be employed. Four years after graduation, Italian ISM graduates are still significantly more likely to be employed than their counterparts (3.6 percentage points), while a similar advantage ( 2.3 percentage points) is no longer significant in the UK. These results are in line with theoretical considerations. Given that participation in ISM is associated with increased interpersonal skills and flexibility in different cultural environments, employers could perceive ISM as a positive signal with which to judge individuals' productivity. This would especially be true in the short term for selection into first employment. In the long term, however, 
signals deriving from first employment experiences are likely to gain greater importance than those from ISM for employment patterns.

In comparison to non-ISM graduates, Italian ISM students are also about 8 percentage points more likely to take up further studies. In the UK, however, participation in ISM does not increase the probability of enrolment in postgraduate studies.

This study hypothesised that the returns to mobility should vary across socio-economic groups and that individuals with a lower socio-economic background would gain more from ISM since through this experience they can acquire human, cultural, and social capital that is important for career decisions and valuable on the labour market. In contrast, advantaged students could, in large part, already build up these skills before engaging in ISM. The empirical analysis reveals that, contrary to expectations, the employment returns associated with ISM are not significantly different between graduates with higher and lower educated parents. However, in Italy, the benefits of ISM in terms of the uptake of postgraduate studies are substantially larger among more disadvantaged students. Given that postgraduate study completion is associated with higher wages, in the long run, student mobility could contribute to narrowing income inequalities between Italian individuals from different socio-economic backgrounds. This result is rather novel as the literature, both on social segregation and ISM, generally focuses on graduates who are in the labour force and does not examine career decisions after graduation.

Results also confirm the theoretical considerations, namely that ISM is likely to provide different signals depending on countries' institutional settings. The interplay between the rigidity of the Italian labour market and the high stratification of the UK tertiary education system is likely to explain our empirical findings of higher ISM returns in Italy than in the UK. This indicates that the country context matters in explaining ISM benefits. Therefore, future research would benefit from more crosscountry analyses of ISM effects. The European Commission Directorate-General for Education, Youth, Sport and Culture is currently investigating the feasibility of a Europe-wide graduate survey, which would make it possible to evaluate the effects of ISM cross-nationally in the future.

Acknowledgements The authors thank Zsuzsa Blaskó, three anonymous referees, and participants of the Lisbon Economics and Statistics of Education conference in Lisbon in January 2019 for valuable comments and suggestions.

Disclaimer: The views expressed are purely those of the writers and may not under any circumstances be regarded as stating an official position of the European Commission. Neither the Higher Education Statistics Agency Limited nor HESA Services Limited accepts responsibility for any inferences or conclusions derived by third parties from data or other information supplied by HESA Services.

Data availability Data used The data collectors, in this case HESA for the UK and ISTAT for Italy, obtained survey participants' informed consent to analyze the collected data for scientific purposes.

\section{Compliance with ethical standards}

Conflict of interest The authors declare that they have no conflict of interest. 
Ethical approval The authors have read the Higher Education information on 'Ethical Responsibilities of Authors' and are not in breach of any of those.

Open access This article is licensed under a Creative Commons Attribution 4.0 International License, which permits use, sharing, adaptation, distribution and reproduction in any medium or format, as long as you give appropriate credit to the original author(s) and the source, provide a link to the Creative Commons licence, and indicate if changes were made. The images or other third party material in this article are included in the article's Creative Commons licence, unless indicated otherwise in a credit line to the material. If material is not included in the article's Creative Commons licence and your intended use is not permitted by statutory regulation or exceeds the permitted use, you will need to obtain permission directly from the copyright holder. To view a copy of this licence, visit http://creativecommons.org/licenses/by/4.0/.

\section{References}

Amit, V. (2010). Student mobility and internationalisation: rationales, rhetoric and institutional isomorphism. Anthropology in Action, 17(1), 6-18.

Becker, G. S. (1976). The economic approach to human behavior. Chicago: The University of Chicago Press.

Bourdieu, P., \& Passeron, J. (1990). Reproduction in education, society and culture. London: Sage.

Breen, R. \& Goldthorpe, J. (1997). Explaining educational differentials. Towards a formal rational action theory. Rationality and Society, 9(3), 275-305.

Bilecen, B., \& Van Mol, C. (2017). Introduction: international academic mobility and inequalities. Journal of Ethnic and Migration Studies, 43(8), 1241-1255.

Britton, J., Dearden, L., Shepartd, N. \& Vignoles, A. (2016). How English domiciled graduate earnings vary with gender, institution attended, subject and socio-economic background. IFS Working Paper W16/06.

Caliendo, M., \& Kopeining, S. (2008). Some practical guidance for the implementation of propensity score matching. Journal of Economic Surveys, 22(1), 31-72.

Coleman, J. S. (1988). Social capital in the creation of human capital. The American Journal of Sociology, 94, 95-S120.

Dornbusch., R., Gentilini, A. \& Giavazzi, F. (2000). Italian labour force participation: Disguised unemployment on campus. ftp://ftp.igier.unibocconi.it/homepages/giavazzi/Bozen05.10.pdf

Di Pietro, G. (2015). Do study abroad programs enhance the employability of graduates? Education Finance and Policy, 10(2), 223-243.

Di Pietro, G. (2019). University study abroad and graduates' employability. IZA World of Labor 2019(109), https://doi.org/10.15185/izawol.109.v2

Dobbins, M., \& Knill, C. (2014). Higher education governance and policy change in Western Europe. International challenges to historical institutions. Hampshire, UK, New York, NY: Palgrave Macmillan.

European Commission. (2009). Erasmus programme: New figures on participation. https://europa.eu/rapid/ press-release_MEMO-09-355_en.htm?locale=en

European Commission. (2018). Erasmus+ Annual report 2017. https://ec.europa.eu/programmes/erasmusplus/about/statistics_en

European Commission. (2019). Education and training monitor 2019. Luxembourg: Publications Office of the European Union.

Eurostat. (2018). Unemployment by sex and age. https://appsso.eurostat.ec.europa.eu/nui/show.do? dataset=une_rt_m\&lang=en

Eurostat. (2017). Share of the population by level of educational attainment, by selected age groups and country 2016. https://ec.europa.eu/eurostat/statistics-explained/index.php?title=File:Share_of_the_ population_by_level_of_educational_attainment,_by_selected_age_groups_and_country,_2016_ (\%25).png

Hauschildt, K., Gwosć, C., Netz, N. \& Mishra, S. (2015). Social and Economic Conditions of Student Life in Europe.https://www.eurostudent.eu/download_files/documents/EIV_Synopsis_of_Indicators.pdf

HESA Student Record 2010/11, HESA Destinations of Leavers from Higher Education Record 2010/11 and HESA Destinations of Leavers from Higher Education Longitudinal Record 2010/11

Jacob, M., Kuehhirt, M., \& Rodrigues, M. (2019). Labour market returns to graduates' international experience: Exploring cross-country variation in Europe. European Sociological review, 35(4), 491-505. 
Kratz, F., \& Netz, N. (2018). Which mechanisms explain monetary returns to international student mobility? Studies in Higher Education, 43(2), 375-400.

Loerz, M., Netz, N., \& Quast, H. (2016). Why do students from underprivileged families less often intend to study abroad? Higher Education, 72(2), 153-174.

Luo, J., \& Jamieson-Drake, D. (2015). Predictors of study abroad intent, participation, and college outcomes. Research in Higher Education, 56, 29-56.

Messer, D., \& Wolter, S. C. (2007). Are student exchange programs worth it? Higher Education, 54(5), 647-663.

Moulin, L., Flacher, D., \& Harari-Kermadec, H. (2016). Tuition fees and social segregation: Lessons from a natural experiment at the University of Paris 9-Duaphine. Applied Economics, 48(40), 3861-3876.

Netz, N., \& Grüttner, G. (2020). Does the effect of studying abroad on labour income vary by graduates' social origin? Evidence from Germany: Higher Education. https://doi.org/10.1007/s10734-02000579-2

Netz, N., \& Finger, C. (2016). New horizontal inequalities in German higher education? Social selectivity of studying abroad between 1991 and 2012. Sociology of Education, 89(2), 79-98.

OECD. (2015). Education at a glance 2015: OECD indicators. OECD Publishing, Paris. https://doi. org/10.1787/eag-2015-en

OECD (2017). OECD Indicators of Employment Protection. https://www.oecd.org/els/emp/ oecdindicatorsofemploymentprotection.htm

OECD (2020). OECD employment status by age and education. https://stats.oecd.org/Index.aspx? DataSetCode $=$ EAG_NEAC\#

Orr, D., Gwosc, C. \& Netz, N. (2011). Social and Economic Conditions of Student Life in Europe. Synopsis of indicators. Final report. Eurostudent IV 2008-2011. Bielefeld: W. Bertelsmann Verlag.

Petzold, K. (2017). Studying abroad as a sorting criterion in the recruitment process: a field experiment among German employers. Journal of Studies in International Education, 21(5), 1-19.

Rodrigues, M. (2013). Does student mobility during higher education pay? Evidence from 16 European countries. JRC Scientific and Policy Report.

Rosenbaum, P., \& Rubin, D. (1985). Constructing a control group using multivariate matched sampling methods that incorporate the propensity score. The American Statistician, 39(1), 33-38.

Roy, A., Newman, A., Ellenberger, T., \& Pyman, A. (2019). Outcomes of international student mobility programs: A systematic review and agenda for future research. Studies in Higher Education, 44(9), $1630-1644$.

Salisbury, M., Umbach, P., Paulsen, M., \& Pascarella, E. (2008). Going global: Understanding the choice process of the intent to study abroad. Research in Higher Education, 50(2), 119-143.

Salisbury, M., An, B., \& Pascarella, E. (2013). The effect of study abroad on intercultural competence among undergraduate college students. Journal of Student Affairs Research and Practice, 50(1), 1-20.

Savickas, M., Nota, L., Rossier, J., Dauwalder, J.-P., Duarte, M. E., et al. (2009). Life designing: A paradigm for career construction in the 21st century. Journal of Vocational Behavior, 75(3), 239-250.

Schnepf, S.V. \& Colagrossi, M. (2020). Is unequal uptake of Erasmus mobility really only due to students' choices? The role of selection into universities and fields of study. Journal of European Social Policies, https://doi.org/10.1177/0958928719899339

Sorrenti, G. (2017). The Spanish or the German apartment? Study abroad related outcomes and its recognition by the labour market. Economics of Education Review, 60, 142-158.

Spence, M. (1973). Job market signaling. The Quarterly Journal of Economics, 87(3), 355-374.

Teichler, U. (2017). Internationalisation trends in higher education and the changing role of international student mobility. Journal of international Mobility, 5, 177-216.

Triventi, M. (2013). Stratification in higher education and its relationship with social inequality: A comparative study of 11 European countries. European Sociological Review, 29(3), 489-502.

Van Mol, C. (2017). Do employers value international study and internships? A comparative analysis of 31 countries. Geoforum, 78, 52-60.

Waibel, S., Rueger, H., Ette, A., \& Sauer, L. (2017). Career consequences of transnational educational mobility: A systematic literature review. Educational Research Review, 20, 81-98.

Wiers-Jenssen, J. (2007). Does higher education attained abroad lead to international jobs? Journal of Studies in International Education, 12, 101-130.

Publisher's Note Springer Nature remains neutral with regard to jurisdictional claims in published maps and institutional affiliations. 